\title{
PERANCANGAN DAN IMPLEMENTASI APLIKASI SISTEM PAKAR UNTUK KERUSAKAN SPEAKER AKTIF DENGAN METODE BACKWARD CHAINING
}

\author{
Made Agung Raharja \\ Program Studi Teknik Informatika \\ Fakultas Ilmu Kesehatan Sains dan Teknologi- Universitas Dhayana Pura \\ agungraharja@undhirabali.ac.id
}

\begin{abstract}
Information technology developments today, both hardware and software, computers have been unable to solve problems faced by humans in various fields so that it can be resolved easily. In everyday practice where a novice technician is in need of the guidance of an expert. Because technicians beginners usually have a fear of taking their own decisions in diagnosing damage to an electronic device. The main components that should be present in an expert system is a knowledge base (knowledge base), inference engine (engine puller conclusion), explanation subsystem (explanatory output subsystem) and the user interface. The implementation phase is done design the system into a software model that has been designed in the previous stage. application of expert systems for active speaker damage by backward chaining method in the programming language Visual Basic 6.0. The results of this research are expert systems to assist in damage to diagnose active speakers can make it easy for novice technicians to find the cause kerusan on the active speaker. Expert system application is an implementation of a design that has been done before for the decision to search for the cause of damage and the active speaker solutions in practice still requires an expert in repairing active speakers.
\end{abstract}

Keywords: expert system, powered speakers

\begin{abstract}
ABSTRAK
Perkembangan teknologi infromasi saat ini, baik hardware dan software, komputer telah mampu menyelesaikan masalah diberbagai bidang yang dihadapi manusia sehingga dapat terselesaikan dengan mudah. Dalam praktek sehari-hari dimana seorang teknisi pemula sangat memerlukan bimbingan dari seorang pakar. Karena teknisi pemula biasanya mempunyai ketakutan untuk mengambil keputusan sendiri dalam melakukan diagnosis kerusakan suatu perangkat elektronik. Komponen utama yang harus ada dalam sebuah sistem pakar adalah knowledge base (basis pengetahuan), inference engine (mesin penarik kesimpulan), explanation subsystem (subsistem penjelas output) dan user interface. Tahap implementasi dilakukan rancang bangun sistem ke dalam suatu perangkat lunak dari model yang telah di rancang pada tahap sebelumnya. aplikasi sistem pakar untuk kerusakan speaker aktif dengan metode backward chaining dalam bahasa pemrograman Visual Basic 6.0. Hasil dari penelitian ini adalah Sistem pakar untuk membantu dalam mengdiagnosa kerusakan pada aktif speaker ini dapat memberikan kemudahan bagi teknisi pemula untuk mencari penyebab kerusan pada aktif speaker. Aplikasi sistem pakar ini merupakan implementasi dari perancangan yang telah dilakukan sebelumnya untuk keputusan pencarian penyebab kerusakan dan solusi pada aktif speaker dalam praktiknya tetap memerlukan seorang yang ahli dalam memperbaiki aktif speaker.
\end{abstract}

Kata Kunci: Sistem pakar, speaker aktif, expert system 


\section{PENDAHULUAN}

Perkembangan teknologi komputer saat ini, baik hardware dan software, komputer telah mampu menyelesaikan masalah diberbagai bidang yang dihadapi manusia sehingga dapat terselesaikan dengan mudah, tepat dan cepat. Salah satu bentuk dari perkembangan teknologi komputer adalah dikembangkannya teknologi kecerdasan buatan sehingga komputer mempunyai intelegensi tertentu yang mampu menyelesaikan masalah yang memerlukan kecerdasan, kepintaran seperti yang bisa dilakukan oleh seorang pakar. Dimana sistem tersebut haruslah berbasis kecerdasan buatan.

Salah satu bagian dari sistem kecerdasan buatan adalah sistem pakar dibidang elektronika. Sistem pakar adalah suatu sistem komputer yang bisa menyamai atau meniru kemampuan seorang pakar (Giarratano dan Riley, 2005), sistem pakar memungkinkan seorang pakar untuk dapat mentransformasi pengetahuannya untuk membantu seseorang awam dalam menyelesaikan suatu permasalahan tertentu. Salah satu teknik untuk membuat komputer mampu mengolah pengetahuan ini disebut teknik kecerdasan buatan (Artificial Intelligence Technique). Dengan pendekatan ini manusia mencoba membuat komputer dapat berpikir seperti cara yang dipakai manusia dalam memecahkan masalah komputer.

Diantara Sistem cerdas yang ada salah satu yang digunakan sebagai system akusisis pengetahuan pakar yaitu Sistem Pakar (expert System). Sistem ini adalah suatu sistem yang dirancang untuk meningkatkan efectivitas pengambilan keputusan dalam memecahkan masalah.

Dalam praktek sehari-hari dimana seorang teknisi pemula sangat memerlukan bimbingan dari seorang pakar. Karena teknisi pemula biasanya mempunyai ketakutan untuk mengambil keputusan sendiri dalam melakukan diagnosis kerusakan suatu perangkat elektronik. Dalam masalah ini akan disajikan cara mendiagnosis kerusakan speaker aktif, karena produk speaker aktif seperti saat ini sangat sering dijumpai dan banyak digunakan oleh masyarakat dan kerusakan sangat sering terjadi.

Berdasarkan uraian diatas terlihat bahwa penggunaan teknologi informasi berbasis komputer akan sangat membantu dalam proses penyelesaiana masalah, maka penulis tertarik untuk merancang dan mengimplementasikan Sistem Pakar untuk membantu mendiagnosa penyebab kerusakan speaker aktif untuk teknisi pemula.

\section{TINJAUAN PUSTAKA}

\section{Pengertian Sistem Pakar}

Sistem pakar dapat didefinisikan sebagai sebuah program komputer berbasis pengetahuan yang dapat memberikan pemecahan setingkat pakar dalam bidang tertentu yang hasil pemecahannya mirip dengan pemecahan yang diberikan oleh pakar sesungguhnya. Basis pengetahuan yang diperoleh diambil dari pengalaman seorang pakar maupun teori-teori yang ada pada bidang yang spesifik saja, oleh karena itu sistem pakar memiliki keterbatasan.

\section{Konsep Sistem Pakar}

Ada enam hal yang menjadi konsep dasar dari sebuah Sistem Pakar,2 yaitu :

\section{Keahlian (Exercise)}

Keahlian dapat diperoleh dari pelatihan / training, membaca atau dari pengalaman. Keahlian itu meliputi :

- Fakta-fakta tentang area permasalahan.

- Teori-teori tentang area permasalahan.

- Aturan-aturan tentang apa yang harus dilakukan dalam situasi permasalahan yang diberikan.

- Strategi global untuk memecahkan masalah.

\section{Pakar (Expert)}

Sulit untuk mendefinisikan apakah yang dimaksud pakar itu. Masalahnya adalah berapa banyak keahlian yang harus dimiliki seseorang agar dapat diklasifikasikan sebagai pakar. Namun berikut dibawah ini, dijelaskan beberapa kualifikasi yang harus dimiliki seorang pakar :

- Dapat mengenal dan merumuskan masalah.

- Dapat memecahkan masalah dengan cepat dan semestinya.

- Dapat menjelaskan suatu solusi.

- Dapat menentukan hubungan.

- Belajar dari pengalaman.

\section{Pemindahan Keahlian (Transferring Expertise)}

Tujuan dari sistem pakar adalah memindahkan keahlian dari seorang pakar ke komputer dan kemudian ke manusia yang bukan pakar. Proses ini meliputi empat kegiatan, yaitu :

- Memperoleh pengetahuan dari pakar.

- Mempresentasikan pengetahuan ke dalam komputer.

- Mengolah pengetahuan sehingga dapat menghasilkan kesimpulan. 
- Memindahkan pengetahuan ke user.

a) Menarik kesimpulan (Inferencing)

Keistimewaan dari sistem pakar adalah kemampuan nalarnya. Komputer diprogram sehingga dapat membuat kesimpulan. Pengambilan kesimpulan ini dilaksanakan dalam komponen yang disebut inference engine.

\section{Aturan (Rule)}

Kebanyakan sistem pakar adalah berbasis rule, pengetahuan disimpan dalam bentuk rule-rule sebagai prosedur pemecahan masalah.

\section{Kemampuan menjelaskan (Explanation Capability)}

Keistimewaan lain dari sistem pakar adalah kemampuan menjelaskan darimana asal sebuah solusi/rekomendasi diperoleh.

\section{Arsitektur Sistem Pakar}

Komponen utama yang harus ada dalam sebuah sistem pakar adalah knowledge base (basis pengetahuan), inference engine (mesin penarik kesimpulan), explanation subsystem (subsistem penjelas output) dan user interface. Secara umum arsitektur sistem pakar 3 dapat dilihat pada gambar 1 .

Sistem pakar disusun oleh dua bagian utama, yaitu lingkungan pengembangan (development environment) dan lingkungan konsultasi (consultation environment). Komponen-komponen sistem pakar dalam dua bagian tersebut ada pada gambar 2.1 sebagai berikut:

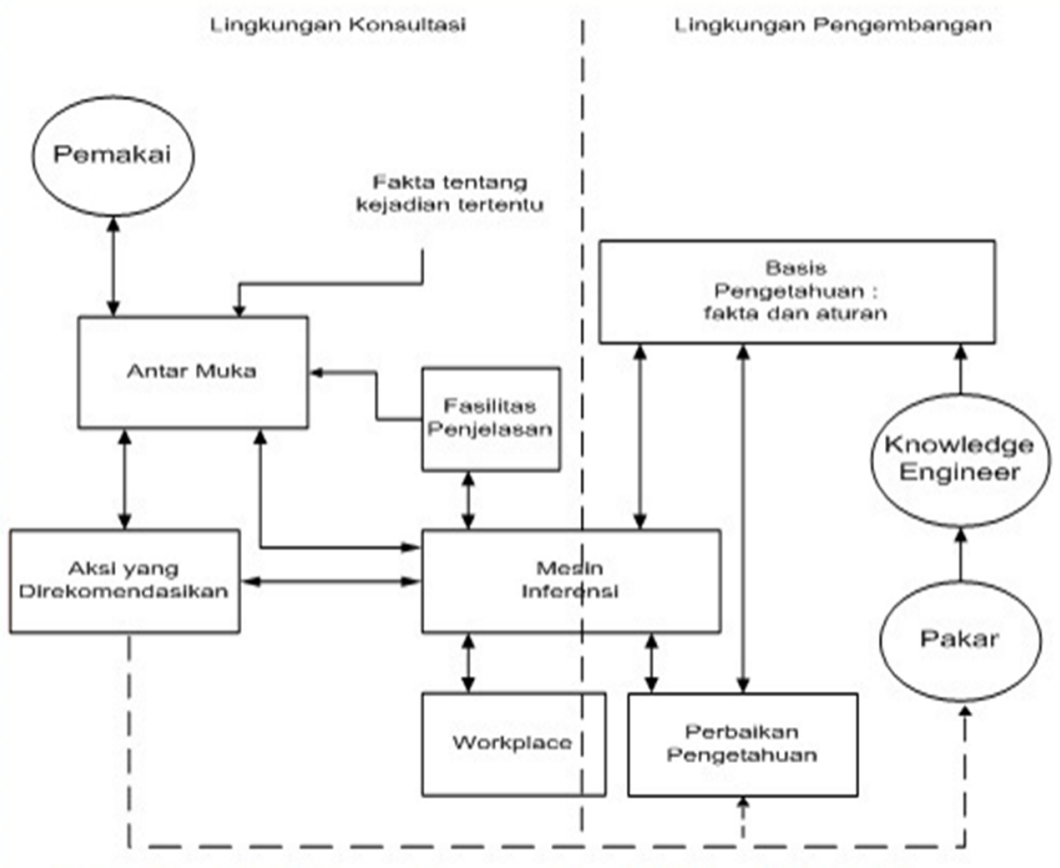

Gambar 1. Arsitektur Sistem Pakar

Secara umum sistem pakar terdiri dari komponen penyusun sebagai berikut:

\section{Knowledge Base ( Basis Pengetahuan )}

Basis pengetahuan merupakan hasil akuisis dan representasi pengetahuan dari seorang pakar. Basis pengetahuan berisi pengetahuan-pengetahuan dalam penyelesaian masalah.

\section{Inference Engine ( Mesin Inferensi )}

Mekanisme inferensi yang utama pada sistem pakar dapat dibedakan menjadi inferensi dengan mekanisme pelacak mundur (backward chaining) dan pelacak maju (forward chaining ). Penalaran dengan Backward chaining dimulai dari sekumpulan hipotesis menuju fakta-fakta yang mendukung hipotesis tersebut. Forward chaining merupakan kebalikan dari Backward chaining, yaitu penalaran di mulai sekumpulan data menuju suatu kesimpulan atau goal.

\section{User interface ( antar mungka pengguna )}

User interface adalah penghubung antar program sistem pakar dengan pengguna 


\section{Backward chaining Dan Forward chaining Forward chaining}

Forward chaining merupakan metode inferensi yang melakukan penalaran dari suatu masalah kepada solusinya. Jika klausa premis sesuai dengan situasi (bernilai TRUE), maka proses akan menyatakan konklusi. Forward chaining adalah data-driven karena inferensi dimulai dengan informasi yang tersedia dan baru konklusi diperoleh. Jika suatu aplikasi menghasilkan tree yang lebar dan tidak dalam, maka gunakan forward chaining.

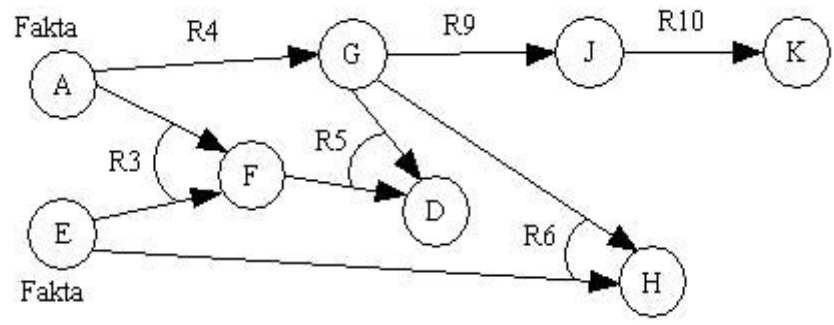

Gambar 2. Forward chaining

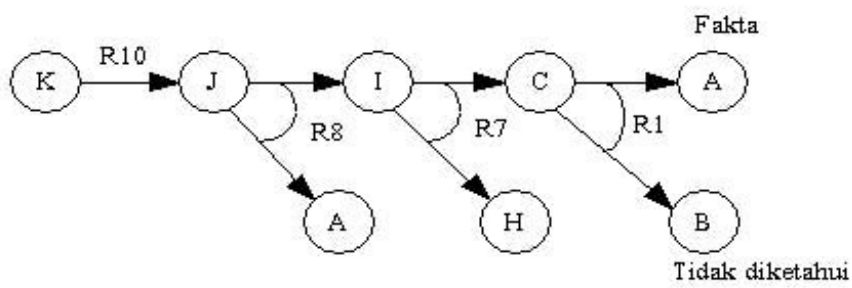

Contoh Backward Chaining gagal

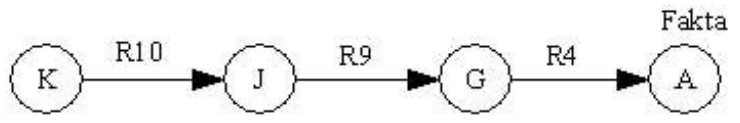

Contoh Backward Chaining berhasil

\section{Gambar 3. Backward chaining}

\section{Backward chaining}

Menggunakan pendekatan goal-driven, dimulai dari harapan apa yang akan terjadi (hipotesis) dan kemudian mencari bukti yang mendukung (atau berlawanan) dengan harapan kita. Sering hal ini memerlukan perumusan dan pengujian hipotesis sementara.

Jika suatu aplikasi menghasilkan tree yang sempit dan cukup dalam, maka gunakan backward chaining.

\section{Metode Pengebangan Sistem Pakar}

1. Basis Pengetahuan (Knowledge Base)

Basis pengetahuan merupakan bagian yang paling penting pada sistem pakar karena keahlian dari pakar disimpan didalamnya. Basis pengetahuan tersebut berisi fakta-fakta yang didapat dari seorang ahli dan diimplementasikan ke dalam sistem komputer dengan menggunakan metode representasi pengetahuan tertentu. Metode representasi pengetahuan adalah cara untuk menstrukturkan pengetahuan yang dimiliki oleh pakar agar mudah diolah oleh komputer.

Representasi sistem pakar berbasis rule adalah kumpulan pengetahuan yang disusun sedemikian rupa dengan struktur IF.. THEN.. dengan relasi AND, OR atau kombinasi AND dan OR 4. Jadi basis pengetahuan merupakan jantung sistem pakar, dimana bagian ini berisi pengetahuan penting untuk mengerti, merumuskan dan memecahkan permasalahan, yang mempunyai dua elemen dasar, yaitu fakta tentang keadaan dan teori tentang area masalah

\section{Inference Engine}

Inference Engine merupakan bagian dari sistem pakar yang bertugas untuk menemukan solusi yang tepat dari banyaknya solusi yang ada. Proses dilakukan dalam inference engine adalah bagaimana pengambilan keputusan terhadap konsultasi yang terjadi dan proses penalaran pada basis pengetahuan yang dimilikinya. 


\section{Explanation Subsystem}

Explanation Subsystem merupakan kemampuan untuk memberikan penjelasan atas sebuah kesimpulan yang diberikan.

\section{User Interface}

User Interface merupakan bagian dari sistem pakar yang berfungsi sebagai pengendali input output. User interface melayani user selama proses konsultasi mulai dari tanya jawab untuk mendapatkan fakta-fakta yang dibutuhkan interference engine sampai menampilkan output yang merupakan kesimpulan/rekomendasi yang dihasilkan oleh interference engine.

\section{Knowledge Base Editor}

Knowledge Base Editor merupakan bagian yang digunakan untuk menambah, menghapus dan memperbaiki basis pengetahuan.

\section{Learning}

Learning adalah suatu proses belajar dari suatu sistem pakar apabila sistem tidak menemukan solusi masalah.

\section{Certainty Factor}

Certainty Factor merupakan faktor keyakinan atas fakta-fakta yang ada.

\section{Aktif Speaker \\ Aktif speaker adalah sebuah alat pengeras suara yang biasa digunakan untuk mendengarkan musik atau keperluan lainnya yang berhubungan dengan pengeras suara. Aktif speaker ini pada dasarnya sama saja dengan amplifire biasa, yang sering kita jumpai pada sound sistem. Hanya saja bentuknya lebih disederhanakan yaitu dengan cara memasang komponen elektronik penguat suara didalam kotak speaker.}

Aktif speaker memiliki beberapa block komponen utama, yaitu :

\section{Power suply}

Adalah komponen elektronika yang terdisi dari transformator step down dan komponen penyearah tegangan serta penyetabil tegangan. Ada juga dalam beberapa speaker aktif seperti speaker aktif untuk komputer yang power suplynya menggunakan rangkaian switching. Tetapi pada dasarnya konsepnya sama saja.

\section{Rangkaian equalizer}

Rangkaian ini berguna untuk mengatur kualitas suara yang di inputkan pada speaker aktif. Rangkaian ini biasanya menggunakan potensio putar atau potensio parametrik untuk mengatur filter suara.

\section{Rangkaian penguat atau amplifire.}

Rangkaian ini berfungsi untuk menerima inputan dari power suflay dan menguatkan signal suara. Sinyal tersebut dinaikan amplitudonya oleh komponen penguat pada rangkaian amplifire. Biasanya menggunakan transistor penguat, dan banyak jenis-jenisnya, sesuai dengan tipe aktif speaker.

\section{Speaker}

Komponen yang satu ini adalah komponen yang sangat penting sebab, komponen inilah yang akan menerjemahkan sinyal suara pada rangkaian amplifire yang berupa gelombanggelombang listrik menjadi suara yang dapat kita dengar.

\section{METODELOGI PENELITIAN \\ Studi Kepustakaan}

Dalam menunjang penelitian akan dilakukan studi pustaka dengan mempelajari beberapa buku teks, jurnal, dan karya ilmiah lainnya yang menunjang beberapa penelitian tentang perancangan dan inplementasi aplikasi sistem pakar untuk kerusakan speaker aktif dengan metode backward chaining.

\section{Analisis dan Perancangan Sistem}

Tahap ini dilakukan perancangan disain sistem yang meliputi : pengumpulan data, proses perancangan sistem, dan disain input serta output. Pengumpulan data atau tahap dokumentasi, yaitu mengadakan pembuatan dokumen yang akan menunjang aplikasi yang akan dibuat agar nantinya sistem bisa dikembangkan lebih lanjut. Dalam tahap ini adalah melakukan pengumpulan dan pengolahan data mengenai sistem pakar untuk kerusakan speaker aktif dengan metode backward chaining.

\section{Implementasi}

Tahap ini dilakukan rancang bangun sistem ke dalam suatu perangkat lunak dari model yang telah di rancang pada tahap sebelumnya. aplikasi sistem pakar untuk kerusakan speaker aktif dengan metode backward chaining dalam bahasa pemrograman Visual Basic 6.0 dengan basis data Microsoft Acces 2007.

\section{Pengujian dan Analisis sistem akhir.}

Pada tahap ini sistem yang telah di buat kemudian dilakukan pengujian sistem dengan menggunakan data yang telah diambil dari berbagai sumber data. Sehingga didapatakan hasil aplikasi sistem pakar untuk kerusakan speaker aktif dengan metode backward chaining. 


\section{PERANCANGAN SISTEM}

Merancang program sistem pakar mendiagnosis kerusakan aktif speaker untuk teknisi pemula ini mempunyai langkah-langkah yang berurutan yaitu :

Merancang database dan rule-rule yang akan dipakai.

Tabel 1. Jenis Kerusakan mati total

\begin{tabular}{|l|l|l|l|}
\hline & Pertanyaan & Ya & Tidak \\
\hline P1 & Apakah ada tegangan pada kabel power? & P2 & S01 \\
\hline P2 & Apakah ada tegangan pada output trafo? & P3 & S02 \\
\hline P3 & Apakah tegangan searah pada rangkaian dioda sesuai? & P4 & S03 \\
\hline P4 & $\begin{array}{l}\text { Apakah tegangan DC yang masuk ke rangkaian, sudah } \\
\text { stabil? }\end{array}$ & S04 & S08 \\
\hline
\end{tabular}

Tabel 2. Jenis Kerusakan Tidak Ada Suara

\begin{tabular}{|l|l|l|l|}
\hline & pertanyaan & ya & tidak \\
\hline P5 & Apakah volume sudah anda putar full? & P6 & S05 \\
\hline P6 & $\begin{array}{l}\text { apakah ada tegangan yang masuk pada rangkaian } \\
\text { amplifire? }\end{array}$ & P7 & S06 \\
\hline P7 & Apakah komponen penguat mengeluarkan tegangan? & P8 & S07 \\
\hline P8 & Apakah ada tegangan yang masuk ke sepeaker? & S09 & S08 \\
\hline
\end{tabular}

Tabel 3. Jenis Kerusakan Ada Derau Suara

\begin{tabular}{|l|l|l|l|}
\hline & pertanyaan & ya & tidak \\
\hline P9 & Apakah ada suara saat anda memutar potensio? & S10 & P10 \\
\hline P10 & Apakah speaker masih mempunyai impedansi yang normal? & P11 & S09 \\
\hline P11 & $\begin{array}{l}\text { Apakah tegangan yang dikeluarkan rangkaian ampli sudah } \\
\text { sesuai? }\end{array}$ & S09 & S07 \\
\hline
\end{tabular}

Tabel 4. Masalah dan Solusi

\begin{tabular}{|l|l|}
\hline & Masalah dan solusinya \\
\hline S01 & $\begin{array}{l}\text { Kemungkinan kabel power AC patah atau tidak bagus! Priksalah kabel tersebut dengan } \\
\text { tester jika tidak nyambung dengan baik segeralah ganti atau disolder dengan sambungan } \\
\text { baru! }\end{array}$ \\
\hline S02 & $\begin{array}{l}\text { Trafo tidak berfungsi, gantilah dengan trafo yang baru atau gunakan output trafo yang } \\
\text { lain dan berikan penyetabil tegangan yang sesuai. }\end{array}$ \\
\hline S03 & Kemungkinan dioda yang anda pasang jebol, gantilah dengan dioda yang baru. \\
\hline S04 & $\begin{array}{l}\text { Kemungkina stop kontak jala-jala listrik anda yang bermasalah, sejauh ini seharusnya } \\
\text { speaker aktif bisa hidup! }\end{array}$ \\
\hline S05 & Mungkin ini keteledoran anda, coba putar volume suara pada speaker aktif! \\
\hline S06 & Kerusakan pada rangkaian power suply, priksa kembali rangkaian! \\
\hline S07 & $\begin{array}{l}\text { Kerusakan pada komponen penguat rangkaian amplifire, gantilah komponen tersebut } \\
\text { dengan tipe yang sama. }\end{array}$ \\
\hline S08 & Sambungan kabel yang tidak sesuai dengan ketentuan. PRIKSA KEMBALI! \\
\hline S09 & Kemungkinan speaker anda sudah jebol! \\
\hline S10 & $\begin{array}{l}\text { Potesio anda kotor, bersihkanlah dengan menggunakan bensin! Atau ganti dengan } \\
\text { fotensio baru! }\end{array}$ \\
\hline
\end{tabular}




\section{Implementasi Sistem}

Tahap implementasi yang paling uatama dalam pembangunan system pakar adalah implementasi aturan atau rules dalam sistem pakar. Pada sub bab ini untuk mengetahui rulerule atau aturan pada penelusuran sistem pakar untuk mengenali jenis penyakit mata pada manusia. Adapun rules yang dibutuhkan adalah sesuai dengan tabel dan hirarki backward chaining yang telah dibahas pada bab sebelumnya. Implementasi Rules (aturan-aturan) dalam sistem pakar untuk diagnosa penyakit mata:

\section{Implementasi Antarmuka}

Pada sub bab implementasi antarmuka sesuai dengan desain antarmuka yang telah dibuat pada bab sebelumnya. Perancangan antar muka dapat dilakukan pengujian dengan mencoba menjalankan aplikasi program yang telah dirancang. Seorang teknisi dapat saja langsung mencoba melakukan pengujian dengan diawali mendaftar sebagai penguna, kemudian mendapatkan ID (nama penggunaan sistem) dan password.

Selanjutnya teknisi langsung dapat berkonsultasi dengan perangkat lunak sistem pakar tersebut.

Setelah konsultasi, maka sistem akan menghasilkan suatu kesimpulan kerusakan speaker.

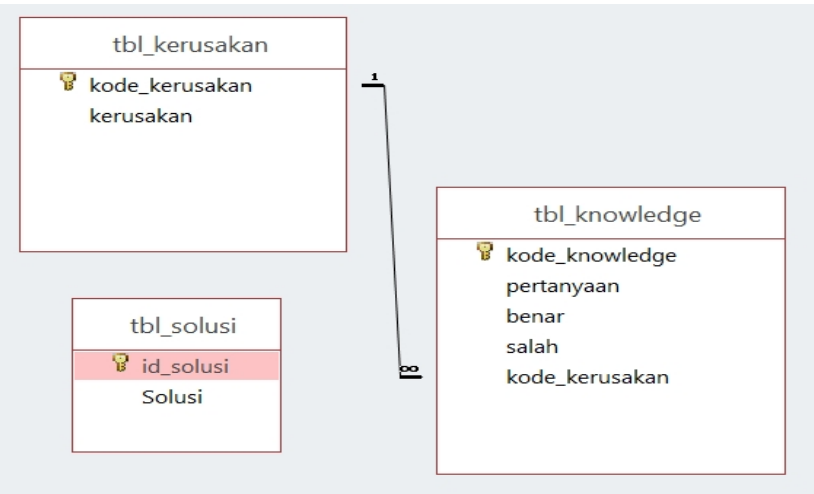

Gambar 4. Database Relationship Sistem Pakar Kerusakan Speaker Aktif

\begin{tabular}{|c|c|c|c|c|}
\hline kode_knowli & pertanyaan & benar & salah & - kode_kerus: T \\
\hline P01 & Apakah ada tegangan pada kabel power? & $\mathrm{PO2}$ & 501 & K01 \\
\hline P02 & Apakah ada tegangan pada output trafo? & P03 & SO2 & K01 \\
\hline P03 & Apakah tegangan searah pada rangkaian dioda sesuai? & P04 & 503 & K01 \\
\hline PO4 & Apakah tegangan DC yang masuk ke rangkaian, sudah stabil? & 504 & SO8 & K01 \\
\hline P05 & Apakah volume sudah anda putar full? & P06 & S05 & $\mathrm{KO2}$ \\
\hline P06 & Apakah ada tegangan yang masuk pada rangkaian amplifire? & P07 & S06 & KO2 \\
\hline P07 & Apakah komponen penguat mengeluarkan tegangan? & P08 & S07 & $\mathrm{KO2}$ \\
\hline P08 & Apakah ada tegangan yang masuk ke sepeaker? & 509 & 508 & $\mathrm{KO2}$ \\
\hline POg & Apakah ada suara saat anda memutar potensio? & $\$ 10$ & P10 & K03 \\
\hline P10 & Apakah speaker masih mempunyai impedansi yang normal? & P11 & 509 & $\mathrm{KO3}$ \\
\hline P11 & Apakah tegangan yang dikeluarkan rangkaian ampli sudah sesuai? & 509 & 507 & KO3 \\
\hline
\end{tabular}

Gambar 5. Tabel Pengetahun Sistem pakar Kerusakan Speaker Aktif

\section{HASIL DAN PEMBAHASAN}

Sistem Pakar sebagai media konsultasi identifikasi kerusakan speaker aktif nerupakan suatu sistem pakar untuk melakukan diagnosis dan memberikan saran untuk cara penanggulangannya berdasarkan gejala-gejala fisik yang terdapat pada speaker aktif tersebut. Pengguna sistem ini dapat dikelompokkan ke dalam dua kelompok, yaitu:
1. Pengguna aktif, yaitu pengguna yang selain melakukan eksekusi juga mengembangkan sistem, termasuk didalamnya yaitu teknisi speaker atau pakar dan knowledge engineer.

2. Pengguna pasif, yaitu pengguna yang hanya melakukan eksekusi sistem, yaitu para user yang ingin melakukan analisis. 
Sistem ini dirancang agar mempermudah bagi orang awam dalam memperbaiki kerusakan speaker. Adapun tampilan implementasi antar muka sistem adalah sebagai berikut
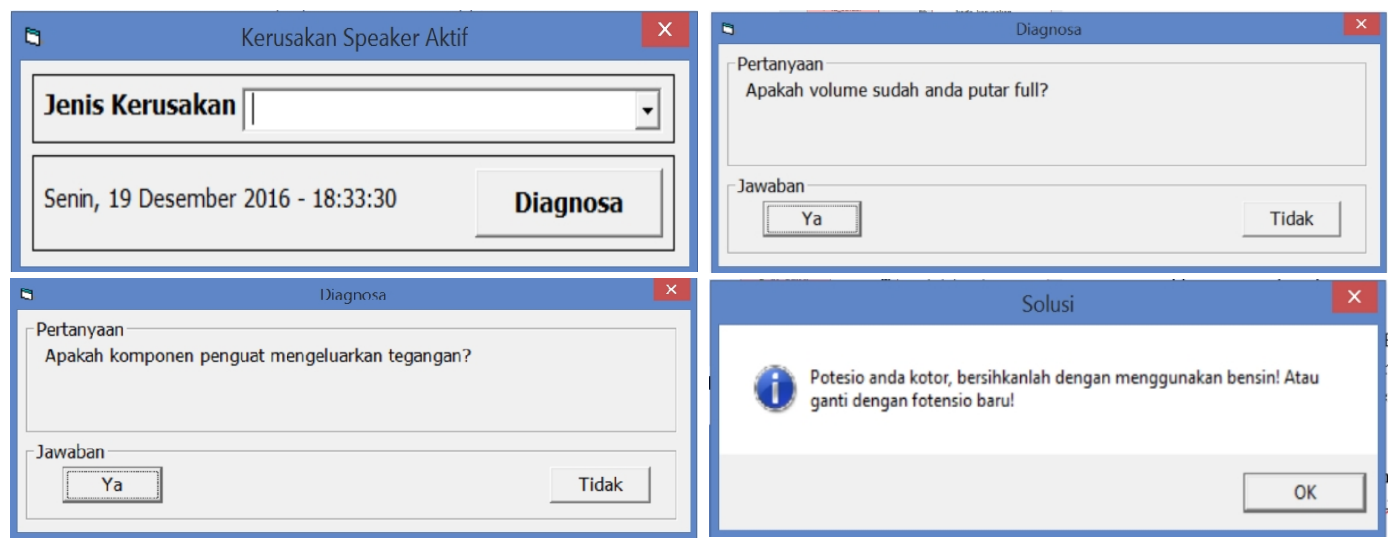

Gambar 6. Tampilan Antar Muka Sistem Pakar Untuk Kerusakan Speaker Aktif

\section{SIMPULAN}

Berdasarkan penelitian yang sudah dilakukan mengenai perancangan dan inplementasi aplikasi sistem pakar untuk kerusakan speaker aktif, maka dapat diambil kesimpulan sebagai berikut:

1. Sistem pakar untuk membantu dalam mengdiagnosa kerusakan pada aktif speaker ini dapat memberikan kemudahan bagi teknisi pemula untuk mencari penyebab kerusan pada aktif speaker.

2. Aplikasi sistem pakar ini merupakan implementasi dari perancangan yang telah dilakukan sebelumnya untuk keputusan pencarian penyebab kerusakan dan solusi pada aktif speaker dalam praktiknya tetap memerlukan seorang yang ahli dalam memperbaiki aktif speaker.

\section{DAFTAR PUSTAKA}

[1] Arhami, M., 2005, Konsep Dasar Sistem Pakar, Andi, Yogyakarta.

[2] Farid Azin, Belajar Sendiri Pemrograman Sistem Pakar, PT. Elekmedia Komputindo - Kelompok Gramedia, Jakarta.

[3] Firebaugh, M.W., 1989, Artificial Intelegence: A Knowledge - Based Approach, Plus-Kent Publishing Company, Boston.

[4] Kusumadewi, S., 2003, Artificial Intelligence, Graha Ilmu, Yogyakarta

[5] Martin, J., \& Oxman, S., 1988, Building Expert Systems A Tutorial, Prentice-Hal, New Jersey.

[6] Turban, E., 1995, Decision Support Systems and Expert Systems, 4th ed.,Prentice-Hall, Inc., New Jersey. PP: $472-679$. 